\title{
ESTAMPAS DESDE LAS TRINCHERAS: JOSÉ ENRIQUE RODÓ Y SU LECTURA DE LA GRAN GUERRA
}

\author{
IMAGES FROM THE TRENCHES: JOSÉ ENRIQUE RODÓ AND HIS \\ READING OF THE GREAT WAR
}

\author{
José Pablo Drews \\ Universidad de la República (Uruguay)
}

Recibido: 20-05-2012

Aceptado: 26-06-2012

\begin{abstract}
Resumen: Sobre la base de algunos recorridos de lectura, explicamos la relación entre el modernismo latinoamericano y la Gran Guerra. Para este fin, en este trabajo se examina la conexión entre literatura y guerra en el pensamiento de José Enrique Rodó. En primer lugar, se presenta el libro El camino de Paros en donde Rodó desarrolla su lectura de la Gran Guerra. Finalmente, y sobre la base de lo anterior, analizamos la obra de Rodó así como algunos de sus textos más importantes.
\end{abstract}

Palabras-clave: José Enrique Rodó, Modernismo, literatura, Gran Guerra.

\begin{abstract}
On the basic of certain reading, we explain the relation between Latin American modernism and his experience of the Great War. For this purpose, this paper examines the connection between Literature and War in the thought of Jose Enrique Rodó. First of all, we present the book El camino de Paros in which José Enrique Rodó developed his reading of the Great War. Finally, and in view of this, we analyze the work of Rodó, as well as some his most important texts.
\end{abstract}

Key-words: José Enrique Rodó, Modernism, Literature, Great War.

Una tarde de invierno de 1916, en la fría Montevideo, en la sala de lectura de la Biblioteca Nacional, el escritor modernista José Enrique Rodó ${ }^{1}$ fue

[1] José Enrique Rodó nace en Montevideo en 1871. En 1895 funda, junto a otros intelectuales uruguayos la Revista nacional de literatura y ciencias sociales, donde publica sus primeros artículos y poemas. En 1898 fue nombrado profesor de literatura en la Universidad de Montevideo, actual Universidad de la República, a pesar de no haber terminado sus estudios universitarios. 
visto por última vez, cabizbajo, abatido en lo personal y lo social. Con su pesada marcha, sus brazos abandonados, y su mirada ausente, el escritor uruguayo daba sus últimos pasos por una ciudad que ya lo había olvidado. Sólo quería huir, viajar, irse a Europa, pero no contaba con recursos propios, ni tampoco con ayuda oficial. Al poco tiempo obtuvo por mediación de un viejo amigo, una corresponsalía en Europa para la revista de Buenos Aires Caras y Caretas.

En el viejo continente corría los tiempos de la Gran Guerra, las resonancias de aquellos días mantenían los espíritus en tensión, y toda la atención mundial estaba concentrada en sus acontecimientos. Así, el escritor modernista se embarca rumbo a Europa en agosto de 1916, fecha en la cual aparece rubricada su primera crónica que envía a la revista titulada: "Cielo y agua", en el cual destaca el siguiente pasaje: "Cae la tarde. Me inclino a contemplar desde la borda, ya los oros y púrpuras de la puesta del sol, ya los alabastros, los mármoles, los ónixes, que la estela del barco compone con la onda trasparente. Balsámica emanación de paz y de misterio parece exhalarse de la soledad infinita» (7).

Su primera parada será en Portugal, donde se entrevista con el presidente de la nación, Don Bernardino Machado². Luego continúa su viaje haciendo una fugaz parada por Madrid y Barcelona, ciudad, esta última, en que se interesó por el nacionalismo catalán, considerándolo "un interesante problema político"”.

Ya en Italia, cumpliendo su misión de corresponsal, envía a la revista bonaerense sus artículos de reflexión estético-filosóficos sobre arte clásico, las cuales se inspiraban en el idealismo humanista de sus libros Ariel y Motivos de Proteo. De todas esas crónicas de viaje nació posteriormente un libro póstumo, titulado El camino de Paros. Este libro de viaje es la ruta bordeada por mármoles sagrados y cipreses, de tierras amigas ya frecuentadas por la fantasía del pensador modernista.

Para comprender sus reflexiones es necesario conocer el ideario de Ariel, publicado en 1900 fue, durante mucho tiempo, la consciencia de América latina. En esta obra son evidentes las huellas de Renan, quien había inyectado su veneno sutilísimo en el escritor modernita, también aparece Taine y el formidable Nietzsche, de quien Rodó escribe: «que tan profundo surco señala en la que podríamos llamar nuestra moderna literatura de ideas» (31). La tesis prin-

En esos años publica La novela nueva (1897) y Rubén Darío (1897). Ya en 1900, ofrece a la juventud hispanoamericana su Ariel, obra que marcará un punto de inflexión en la cultura americana. Luego vendrán los libros Liberalismo y Jacobinismo (1906), Motivos de Proteo (1913), y el libro póstumo El camino de Paros (1918). Encontrándose ya en Italia, como corresponsal de la revista argentina Caras y Caretas, cayó enfermo en Palermo, donde dejó de existir en septiembre de 1917.

[2] Bernardino Luis Machado (1851-1944), fue presidente de la República de Portugal desde 1915 hasta 1917, fecha en que la junta militar disuelve el Congreso y los destituye.

[3] Cfr. J. Enrique Rodó, (1968).

THÉMATA. Revista de Filosofía, Nº48 julio-diciembre (2013) pp.: 135-142 doi: 10.12795/themata.2013.i48.11 
cipal del libro es una defensa de los valores del humanismo greco-latino frente al positivismo de cuño sajón, el utilitarismo, la industrialización del mundo, la mecanización del alma, que Rodó veía representado fundamentalmente en Estados Unidos.

Así bajo ese manto de ideas humanistas, el uruguayo ilumina sus reflexiones sobre las "ciudades con alma", que luego envía a la revista. Aparece su recuerdo de Pisa, nobiliaria y taciturna, o de esa Florencia, "arrobada en la visión de sus divinos mármoles", la semifrancesa y grave Turín, o esa gigantesca Roma, ciudad orbe, ciudad arquetipo, "donde todas las demás de nuestra civilización están potencialmente, como los astros del cielo, en el claustro materno de la primitiva nebulosa» (J. E. Rodó, 1968, p. 80).

Pero en sus crónicas de viaje, donde hay mucho color, mucha evocación eficaz, y sobre todo paisajes dibujados, también alterna sus impresiones sobre la Gran Guerra, en artículos como "La esperanza de Nochebuena", "Anécdotas de la guerra" y sobre todo en "Un documento humano", un relato desgarrador sobre la realidad en las trincheras. Es éste, en efecto, el artículo con el cual el escritor modernista pone al corriente a los lectores de Caras y Caretas acerca del horror de la guerra.

\section{Un diario psicológico}

Ya en Turín, en diciembre de 1916, Rodó quien se encontraba en el taller de Leonardo Bistolfi", «rodeado de formas estatuarias que hablan del "dolor y la muerte”» (J. Rodó, 1968, p. 60), leía junto a éste y otros amigos, un curioso manuscrito, un cuaderno de memorias, un diario psicológico de un oficial del ejercito austriaco, quien había anotado impresiones de la vida de campamentos y trincheras, cuyas páginas también hablan de dolor y de muerte. Eran estas las anotaciones de un soldado anónimo que cayó prisionero en el bando italiano en la toma de Gorizia ${ }^{5}$, y cuyo manuscrito recuperado por las tropas italianas circulaba entre los intelectuales de Turín. Así, el escritor modernista que tuvo ocasión de leer ese verdadero "documento humano", una confesión libre de artificios, transcribe algunos pasajes de ese manuscrito, y también los comenta brevemente para los lectores de la revista porteña.

En suma sobresale, según Rodó, un eficaz instinto de expresión del soldado anónimo, su fina ironía, su antipatriotismo, pero sobre todo el mensaje, que el uruguayo hace suyo, de la desmitificación de la guerra. Ante ello, es bueno recordar, para comprender el mensaje del manuscrito anónimo, el contexto

[4] Leonardo Bistolfi (1859-1933), fue un escultor y político italiano, el principal exponente del simbolismo italiano.

[5] Gorizia es un municipio italiano que en la actualidad linda con Eslovenia. Bordeada por el río Isonzo, fue famosa por una serie de batallas libradas en la Gran Guerra, entre los ejércitos del Imperio austrohúngaro y del Reino de Italia, entre junio de 1915 y noviembre de 1917.

THÉMATA. Revista de Filosofía, $\mathrm{N}^{\circ} 48$ julio-diciembre (2013) pp.: 135-142 doi: 10.12795/themata.2013.i48.11 
eufórico, el repentino entusiasmo, que el estallido de la Gran Guerra había despertado en los jóvenes europeos. Así lo rememora el escritor austriaco Stefan Zweig: «de pronto flameaban banderas y por doquier se oían bandas de música, los reclutas desfilaban triunfantes, con los rostros iluminados, porque la gente los vitoreaba, a ellos, los hombrecitos de cada día, en quienes nadie se había fijado nunca y a quienes nadie había agasajado jamás» (S. Zweig, 2002, p. 287).

La juventud, heroica y orgullosa, en su gran mayoría se sentía que participaba en la "Historia Universal", que vivía una hora irrepetible. «El oficinista, el zapatero, a todos ellos de repente se les abría en sus vidas otra posibilidad, más romántica: podían llegar a héroes; y las mujeres homenajeaban ya a todo aquel que llevara uniforme» (Idem).

Así pues, toda esa credulidad ingenua, todo ese infantilismo, esos restos románticos, son totalmente desenmascarados a través del diario psicológico del soldado anónimo. En efecto, los pasajes desgarradores que el escritor uruguayo transcribe para el público latinoamericano representan una crítica a la guerra desde dentro, en la medida que permite desentrañar la realidad oculta en el fondo de ese momento, ya que están escritos con sangre de las trincheras, dejando así un poderoso reflejo interior del soldado, ecos dispersos, flotantes "que vienen del hondo sentimiento colectivo, de la consciencia profunda de la humanidad".

Comienza Rodó trasladando los apuntes fechados del manuscrito, los cuales, como se verá, resultan interesantes para comprender el estado de alma de ese infortunado dentro de la guerra. He aquí algunos de los pasajes más importantes del diario:

15 de Julio._Los italianos cantan mientras huelgan. ¿Cantan para darse coraje o porque se sienten coristas de opereta hasta en presencia de la muerte? (J. Rodó, 1968, p. 60).

Luego de esta fina ironía contra los italianos, lanza sus dardos sobre el lado de Alemania, disparando contra parte de su cultura:

18 de Julio._ Se dice que el pobre de Oin se ha suicidado. Tal vez se ha suicidado de miedo. "Será enterrado en la bocacalle aquel que se dé la muerte por su mano", dice Heine. ¡Ah, los alemanes tienen un gran poeta, que es Heine, pero no lo quieren reconocer por suyo! ¿Quién me objeta con Goethe? Ciertamente, Goethe era tudesco, ¿pero acaso era Goethe poeta?... (Ibid, p 61).

A continuación dispara contra las patrias, las naciones, contra ese sentimiento de patriotismo que lleva a antiguos vecinos a cometer las peores atrocidades entre sí:

20 de Julio._ Hoy se ha conmemorado el aniversario de Lisa. jJe m'en fiche! (traduzco -escribe Rodó- por esa frase francesa la expresión, mucho más ruda, del original). Ocasión para misas campales y discursos patrióticos... El capellán ha dicho hoy tantas misas que ha de haberse embriagado de la sangre de Cristo... Banquetes, brindis, vino espumante... No hay duda: ¡una estupenda cosa el patriotismo! ¿Se me reprochará que yo no lo sienta?

THÉMATA. Revista de Filosofía, Nº48 julio-diciembre (2013) pp.: 135-142 doi: 10.12795/themata.2013.i48.11 
Estampas desde las trincheras: José Enrique Rodó y su lectura de la Gran Guerra

Perdón: yo nací eslavo, pasé la infancia en Viena, la adolescencia en Budapest, tres años en Suiza, seis en París... Dígaseme en consciencia si un pobre diablo como yo, que ni siquiera sabe lo que es, puede sentir sinceramente patriotismo austriaco (Idem).

A estas notas sigue una nota sarcástica, de mucha ironía, de humor heiniano según el escritor uruguayo que la transcribe y la comenta brevemente:

22 de Julio._ ¡Hora trágica! Y, sin embargo, es necesario que ría. Un casco de granada ha mutilado de la peor manera a mi asistente. ¡Desventurado inválido que, a diferencia de los otros, no podrá enseñar sus gloriosas heridas a las muchachas de su aldea! (Ibid, p. 62).

A partir de esa fecha, de ese registro, comienzan las pinceladas de realidad guerrera, del horror, del asco del heroísmo y la gloria:

25 de Julio._ ¡Hora trágica! El cansancio me había rendido al sueño. Me desperté del súbito, y no por el estampido del cañón. Es que sentía resbalar por las mejillas una substancia blanda, caliente, que me rozaba los labios... ¡Oh, Dios mío! Eran los sesos de un pobre cabo que yacía a corto trecho de mí, con la cabeza hecha pedazos... iNunca más me libraré en la vida de esta horrible impresión! (Idem).

Expresiones crudas, enérgicas, notas todas salpicadas por lo monstruoso, por el espectáculo de la guerra, las cuales como se puede apreciar lo llevan poco a poco a la locura:

30 de Julio._ No es ciertamente una diversión estar en las trincheras bajo el fuego terrible de los italianos. ¡Pródigos como grandes señores estos bellos tipos! Derrochan insensatamente sus municiones, y les pasará al fin como a los franceses y a los rusos. Lo cual me tiene sin cuidado. En cambio me importa mucho el espectáculo que se desenvuelve a mí alrededor. Cabezas, mochilas, piernas, brazos, y pelotones de tierra, palos de carpas, descuajadas vísceras: todo volando en confusión por el aire. Es una batahola como si el mundo volviera nuevamente al caos (Idem).

En las siguientes anotaciones, luego de bailar con la muerte en las trincheras, nuestro soldado anónimo, apela a la piedad materna como actitud vengadora:

31 de Julio._ Noche terrible. Quisiera estar ya muerto. Creo que es mejor conclusión morir que perder el juicio. Pienso en los pintores de batallas, y pregunto cuál sería el poeta capaz de poner en bellas rimas estos vientres destripados, estos pingajos de carne, estos torsos semidesnudos, esos lodazales de sangre, esos sesos fuera de su cráneo... ¡Cuánto daría por traer aquí a las madres que tengan un hijo en la guerra! ... ¡Ah, si las madres vieran esto, yo digo que al cabo de una semana no quedaría en ninguna parte del mundo, reyes, emperadores ni generales! Pero las infelices se imaginan, allá en su casa, que los heridos son cuidadosamente puestos en cura, y que a los muertos se les entierra con un

THÉMATA. Revista de Filosofía, Nº48 julio-diciembre (2013) pp.: 135-142 doi: 10.12795/themata.2013.i48.11 
crucifijo entre las manos... (Ibid, pp.62-63).

Las siguientes notas muestran ya arrebatos de trastorno mental, pero con curiosos rasgos de ironía y agudas observaciones:

2 de Agosto._El médico opina que no es cosa de descuidar esto que tengo. Yo estoy mal, muy mal, sin duda. Dicen que deliro de noche. El alimento me da náuseas- iSiento en todo lo que como el sabor de los sesos del cabo! (Idem).

En líneas más abajo, se pude leer como se agudiza su locura:

7 de Agosto._ Lloraría de este terrible dolor de cabeza que tengo. Para quien ha danzado en las trincheras la danza de la muerte, sólo queda abierto un camino: el del hospital de locos (Ibid, p. 64).

Finalmente, el escritor modernista elige para cerrar su transcripción a la revista Caras y Caretas, las siguientes anotaciones, donde el soldado anónimo, ya batido mentalmente, penetra en cotas muy profundas del alma humana:

11 de Agosto._ Ayer he tenido fiebre. Me siento muy sin fuerzas. Estoy solo, contemplando la puesta del sol. Los cipreses del huerto se tiñen de púrpura y de oro. Parece que una cosa dura como el acero hubiera chocado con mi alma y la hubiera roto en pedazos... Veo desde aquí la hortelana que baja a recoger el agua y luego la vierte en la pileta para que la beban los bueyes. Hace como la guerra, que saca a los hombres de su casa y los vuelca en las trincheras para que la muerte se los trague... No concibo cosa más estúpida que la guerra de medio mundo contra el otro medio, tanto más cuanto que creo que después de ella las cosas quedarán, poco más o menos, como antes. ¡Ah, el cuerpo muerto de Luis XVI está esperando a sus colegas, y si tuviera la cabeza pegada al trono se reiría! (Idem).

\section{Consideraciones finales}

Este relato, diario íntimo, manuscrito psicológico, invita a investigar algunas consideraciones estético-filosóficas del ideario de Rodó, en la medida que éste a través de la expresión "un documento humano" para referirse a las notas del soldado anónimo, intenta trasmitir parte de sus ideas estético-morales.

Para empezar, la cuestión de la forma en un autor como Rodó nunca es secundaria, sino que «las ideas adquieren alas potentes y veloces, no en el helado seno de la abstracción, sino en el luminoso y cálido ambiente de la forma» (J. Rodó, 1985, p. 21). Hay en todo ello, más allá de sus meros rasgos estetizantes, una tenaz visión filosófica que fundamenta el modernismo literario $^{6}$. En efecto, este movimiento mostró un "deseo de belleza", sin por ello dejar

[6] Thomas Ward, (2002).

THÉMATA. Revista de Filosofía, Nº48 julio-diciembre (2013) pp.: 135-142 doi: 10.12795/themata.2013.i48.11 
de ser "convincente y profundo en ideas", siendo el nihilismo, el simbolismo y el decadentismo, las principales doctrinas que lo influyeron.

En función a este marco teórico, y tomando como clave dos ideas centrales que navegan en interior del pensamiento del escritor uruguayo, se buscará "comprender" el valor estético-moral de ese admirable "documento humano".

Así, en primer lugar aparece en el ideario de Rodó la noción que bien podríamos llamar: "pesimismo valiente", que tiene la significación de un "optimismo paradójico", y que consiste en que: «muy lejos de suponer la renuncia y la condenación de la existencia, ellos propagan [los pesimistas valientes], con su descontento de lo actual, la necesidad de renovarla» (J. Rodó, 1985, p. 9). Lo que importa es, por tanto, "la posibilidad de llegar a un término mejor por el desenvolvimiento de la vida" (Ibid, p. 10); se intenta mejorar la condición humana a base de un "desenmascaramiento" de la falsa moral.

En ese sentido, el soldado anónimo representa para el escritor modernista un fino poeta, un artista, que con su eficaz instinto de expresión es capaz de "desentrañar" la falsa moral que sustenta el espíritu de la guerra. Es, sin duda, un "pesimista valiente", que nos regala una poderosa imagen de su personalidad, quien con sus sátiras dibuja imágenes penetrantes, insustituibles, «como estampadas por el agua fuerte sobre lámina de acero» (J. Rodó, 1968, p. $60)$.

En segundo lugar, y en conexión con la anterior idea, Rodó, en Ariel, nos habla del "entendimiento de la hermosura", en la cual le corresponde al genio, al artista, descubrir y revelar la íntima belleza de las ideas, para la eficacia de las revoluciones morales. En ese sentido, el escritor modernista, colocó la moral, la vida y la hermosura en un solo plano, donde lo ético y lo estético se unen para formar una «ley moral como una estética de la conducta» (J. Rodó, 1985, p. 18). Aun así, el punto más importante se resume en la máxima "hacer la vida más intensa”, lo cual significa mejorar la condición humana, superar la condición de rebaño.

Por consiguiente, ese "entendimiento de la hermosura", que bien se puede entender como una "ética de la sinceridad", nos sirve para comprender el valor estético-moral de las confesiones del soldado anónimo, en la medida que estas confesiones personales, escritas con la absoluta sinceridad del testimonio íntimo, revelan el fondo oculto de esa alma atormentada. Y, en ese sentido ese "documento humano" escrito en las trincheras alumbra una preciosa luz para

[7] Para este tema en concreto se tomará la teoría de la recepción estética, deudora en gran medida de la hermenéutica filosófica de G. Gadamer. Hans Jauss, padre fundador de la Rezeptionsästhetik y discípulo del autor de Verdad y método, sostiene que en el proceso de interpretación de una obra influye el marco histórico del lector, su "horizonte de expectativas", lo cual no quiere decir que esa obra tenga una lectura acababa, fija, sino que el proceso de comprensión es interactivo entre el lector y el texto. La comprensión es, por tanto, una "fusión de horizontes", que consolida, en parte, el juicio interpretativo acerca de una obra, sea literaria o filosófica, de una época o una cultura en particular. Véase Hans Jauss, (1986).

THÉMATA. Revista de Filosofía, №48 julio-diciembre (2013) pp.: 135-142 doi: 10.12795/themata.2013.i48.11 
que el hombre del porvenir se proponga desentrañar la realidad oculta, muchas veces olvidada por los manuales de historia, de ese momento extraordinario de la historia del mundo. Asimismo, este diario vale también como verdadero documento literario, como confesión íntima, siendo ésta la parte más interesante de la historia, según Rodó, ya que en primer lugar no nace para la imprenta, para los otros, sino de la absoluta sinceridad de su testimonio ${ }^{8}$.

Así, para ir resumiendo, se puede decir que estas fueron las impresiones de la guerra en el escritor uruguayo, las cuales trasmitió a los lectores de la revista porteña. Resulta curioso que éstas fueran reproducidas junto a sus mejores postales viajeras, intentando captar en estas el alma de esas ciudades de mármoles sagrados, de pueblos que tuvieron el más hondo entendimiento de verdad y de hermosura. Tal vez bajo ese manto de belleza el escritor modernista haya intentado alimentar el espíritu con el arte clásico para superar esas horas de muerte y de dolor.

\section{Bibliografia:}

Ángel Rama, Rubén Darío y el modernismo, Caracas/Barcelona, Alfadil Ediciones, 1985.

Hans Jauss, Experiencia estética y hermenéutica literaria, Madrid, Taurus, 1986. Traducción de Jaime Siles y Ela M. ${ }^{a}$ Fernández- Palacios.

José Enrique Rodó, Ariel, Caracas, Biblioteca Ayacucho, 1985.

_ Motivos de Proteo, Caracas, Biblioteca Ayacucho, 1985

1968.

_El camino de Paros, Montevideo, Centro Editor de América Latina,

Stefan Zweig, El mundo de ayer, Barcelona, Acantilado, 2002. Traducción de J. Fontcuberta y A. Orzeszek.

Thomas Ward, "Los posibles caminos de Nietzsche en el Modernismo", Nueva Revista de Filología Hispánica, julio-diciembre, año/vol. L, número 002, pp. $489-515$.

[8] El tema sobre el verdadero valor literario de una obra de arte fue una cuestión muy debatida entre los modernistas, en la medida que veían como el arte se transformaba en un producto de mercado, sometido por tanto, a las leyes de la competencia. El nuevo orden impulsado por los burgueses producía así la división del trabajo y la instauración del mercado, y en ese nuevo escenario el artista se veía condenado a desparecer. No había por entonces un público que pudiera sostener la producción literaria, como sí, en cambio, ya lo había para los bienes de consumo. Es en ese sentido que escribe Rodó sobre el valor literario del manuscrito del soldado anónimo ya que éste parte de la «absoluta sinceridad del testimonio íntimo y sin pensar que existen en el mundo imprenta y literatura» (Rodó, 1968, p. 64). Para un análisis detallado sobre el tema de los modernistas en el mercado económico véase Ángel Rama (1985).

THÉMATA. Revista de Filosofía, Nº 48 julio-diciembre (2013) pp.: 135-142 doi: 10.12795/themata.2013.i48.11 